\title{
Front Matter: Volume 9294
}

, "Front Matter: Volume 9294," Proc. SPIE 9294, International Symposium on Optoelectronic Technology and Application 2014: Development and Application of High Power Lasers, 929401 (9 December 2014); doi: 10.1117/12.2180170

SDIE Event: International Symposium on Optoelectronic Technology and SPIE. Application 2014, 2014, Beijing, China 


\title{
PROCEEDINGS OF SPIE
}

\section{International Symposium on Optoelectronic Technology and Application 2014 \\ Development and Application of High Power Lasers}

\author{
Lin Li \\ Pu Wang \\ Jun Zhou \\ Lijun Wang \\ Yong Cheng \\ Editors
}

13-15 May 2014

Beijing, China

Organized by

Photoelectronic Technology Committee, Chinese Society of Astronautics (China)

Sponsored by

Chinese Society of Astronautics (China)

China High-tech Industrialization Association (China)

Technical Cosponsor and Publisher

SPIE

Volume 9294 
The papers included in this volume were part of the technical conference cited on the cover and title page. Papers were selected and subject to review by the editors and conference program committee. Some conference presentations may not be available for publication. The papers published in these proceedings reflect the work and thoughts of the authors and are published herein as submitted. The publisher is not responsible for the validity of the information or for any outcomes resulting from reliance thereon.

Please use the following format to cite material from this book:

Author(s), "Title of Paper," in International Symposium on Optoelectronic Technology and Application 2014: Development and Application of High Power Lasers, edited by Lin Li, Pu Wang, Jun Zhou, Lijun Wang, Yong Cheng, Proceedings of SPIE Vol. 9294 (SPIE, Bellingham, WA, 2014) Article CID Number.

ISSN: 0277-786X

ISBN: 9781628413809

Published by

SPIE

P.O. Box 10, Bellingham, Washington 98227-0010 USA

Telephone +1 3606763290 (Pacific Time) · Fax +1 3606471445

SPIE.org

Copyright (C) 2014, Society of Photo-Optical Instrumentation Engineers.

Copying of material in this book for internal or personal use, or for the internal or personal use of specific clients, beyond the fair use provisions granted by the U.S. Copyright Law is authorized by SPIE subject to payment of copying fees. The Transactional Reporting Service base fee for this volume is $\$ 18.00$ per article (or portion thereof), which should be paid directly to the Copyright Clearance Center (CCC), 222 Rosewood Drive, Danvers, MA 01923. Payment may also be made electronically through CCC Online at copyright.com. Other copying for republication, resale, advertising or promotion, or any form of systematic or multiple reproduction of any material in this book is prohibited except with permission in writing from the publisher. The CCC fee code is 0277-786X/14/\$18.00.

Printed in the United States of America.

Publication of record for individual papers is online in the SPIE Digital Library.

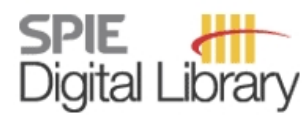

SPIEDigitallibrary.org

Paper Numbering: Proceedings of SPIE follow an e-First publication model, with papers published first online and then in print and on CD-ROM. Papers are published as they are submitted and meet publication criteria. A unique, consistent, permanent citation identifier (CID) number is assigned to each article at the time of the first publication. Utilization of CIDs allows articles to be fully citable as soon as they are published online, and connects the same identifier to all online, print, and electronic versions of the publication. SPIE uses a six-digit CID article numbering system in which:

- The first four digits correspond to the SPIE volume number.

- The last two digits indicate publication order within the volume using a Base 36 numbering system employing both numerals and letters. These two-number sets start with 00, 01, 02, 03 , $04,05,06,07,08,09,0 A, 0 B \ldots 0 Z$, followed by 10-1Z, 20-2Z, etc.

The CID number appears on each page of the manuscript. The complete citation is used on the first page, and an abbreviated version on subsequent pages. Numbers in the index correspond to the last two digits of the six-digit CID number. 


\title{
Contents
}

\author{
$\checkmark \quad$ Authors \\ vii Symposium Committees \\ xi Conference Committee \\ xiii Introduction
}

\section{DEVELOPMENT AND APPLICATION OF HIGH-POWER LASERS}

929402 Spatially flat in-phase supermode in multi-core photonic crystal fibers by manipulating refractive of doped region [9294-1]

929403 Factors influencing efficiency of laser wireless power transmission system for micro unmanned aerial vehicles [9294-8]

929404 L-band double Brillouin frequency spaced tunable multi-wavelength Brillouin fiber laser [9294-15]

929405 Design of large mode area, mode selection fiber [9294-10]

929406 A new method for all optical space network based on fiber laser phase array technology [9294-17]

929407 A dual-wavelength erbium-doped fiber laser based on fiber grating pair [9294-16]

929408 40nm tunable multi-wavelength fiber laser [9294-14]

929409 Research on the effect of coherent beam combination based on array of liquid crystal optical phased arrays [9294-20]

9294 OA Influence of laser energy deposition on mach reflection of inlet [9294-26]

9294 OB Experimental research on thulium-doped fiber ASE characteristics pumped by $976 \mathrm{~nm}$ LD [9294-18]

9294 0C Application and the key technology on high power fiber-optic laser in laser weapon [9294-23]

9294 OD $980 \mathrm{~nm}$ narrow linewidth Yb-doped phosphate fiber laser [9294-5]

9294 OE Experimental demonstration of adaptive fiber-optics collimator based on flexible hinges [9294-27]

9294 OF A fused side-pumping optical fiber coupler based on twisting [9294-34] 
9294 OG Interface reaction of optical glass fiber sintered with low-temperature sealing glass [9294-13]

$9294 \mathrm{OH} \quad$ A review on fiber laser striation-free cutting for thick section stainless steel [9294-11]

9294 Ol New laser communication and laser ranging of integration source system [9294-35]

9294 0J Ship movement simulation using the liquid crystal spatial light modulator [9294-3]

9294 OK Research on laser diode end-pumped Er:YSGG/YSGG composited crystal at $2.79 \mu \mathrm{m}$ [9294-7]

9294 OL Performance calculation and simulation system of high energy laser weapon [9294-6]

9294 OM First principles study on optical properties of GaAs saturable absorbers with native defects [9294-4]

9294 ON Single-pulse driven, large-aperture $2 \times 1$ array plasma-electrodes optical switch for SG-II upgrading facility [9294-32]

$929400 \quad$ Numerical prediction of micro-channel LD heat sink operated with antifreeze based on CFD method [9294-22]

9294 OP Key techniques for space-based solar pumped semiconductor lasers [9294-36]

$9294 \mathrm{OQ}$ Investigation on the influence of BBO thermal-induced phase mismatching in $266 \mathrm{~nm}$ UV laser conversion efficiency [9294-30]

9294 OR Research on the laser transmission characteristics simulation and comprehensive test in complex channel environment [9294-37]

9294 OS Research on energy transmission calculation problem on laser detecting submarine [9294-38]

9294 OT Low-level Ga-Al-As laser irradiation enhances osteoblast proliferation through activation of Hedgehog signaling pathway [9294-25]

9294 OU The study of $3.2 \mathrm{~mJ}$ picosecond regenerative amplifier at $2 \mathbf{~ k H z}$ [9294-40]

9294 OV $\quad 40 \mathrm{~W}$ high beam quality $532 \mathrm{~nm}$ green laser with LBO intracavity-frequecy-doubling [9294-44]

9294 OW Optimization of $1300 \mathrm{~nm}$ quantum well laser on GaAs substrates [9294-12]

9294 0X External folded cavity optical feedback diode laser with megahertz relative linewidth [9294-9] 


\section{Authors}

Numbers in the index correspond to the last two digits of the six-digit citation identifier (CID) article numbering system used in Proceedings of SPIE. The first four digits reflect the volume number. Base 36 numbering is employed for the last two digits and indicates the order of articles within the volume. Numbers start with 00, 01, 02, 03, 04, 05, 06, 07, 08, 09, OA, OB...0Z, followed by 10-1Z, 20-2Z, etc.

\begin{tabular}{|c|c|}
\hline Ai, Yong, OJ & Liu, Guoying, OG \\
\hline An, Ning, OW & Liu, Jianhua, OR \\
\hline An, Yan, OS & Liu, Jingjiao, 06 \\
\hline Bai, Zhen-ao, oU & Liu, Min, OJ, OL \\
\hline Bai, Zhen-Xu, OU & Liu, Shujie, OT \\
\hline Chang, Xinzu, OF & Liv, Xianzhu, 06 \\
\hline Chen, Jian, 09 & Liu, Xiaoguang, 03 \\
\hline Chen, Yingxin, OT & Liu, Xiao-long, OP \\
\hline Chen, Zilun, OF & Liu, Xuesheng, OV \\
\hline Chi, Junjie, OD & Liu, Xun, 03 \\
\hline Cong, Wen, OM & Liu, Yang, $0 \bigcirc$ \\
\hline Ding, Ye, 05 & Liu, Youqiang, OV \\
\hline Dong, Keyan, 04, 08 & Liu, Zhi, OR \\
\hline Fan, Zhong-wei, OU & Long, Xingwu, OX \\
\hline Fang, Xuan, OW & Luo, Zhifu, OX \\
\hline Fu, Huaixiu, OK & Ma, Wanzhuo, OB \\
\hline Fu, Qiang, OI, OR, OS & Ma, Xiaohui, 05, ow \\
\hline Gao, Duo-rui, Ol & Ma, Yan-xing, OE \\
\hline Gao, Xiping, OG & Meng, Haihong, OC \\
\hline Han, Bin, OG & Peng, Chen, OK \\
\hline Han, Jian, 06, OB & Qu, Zhou, OC, OT \\
\hline Han, Wei-hua, OP & Shan, Xin, OJ \\
\hline $\mathrm{He}$, Yang, OP & Shen, Benjian, OK \\
\hline Hong, Yanji, OA & Shi, Haodong, Ol \\
\hline Hu, Haowei, OD & Si, Lei, OE \\
\hline Hu, Yuan, 06 & Song, Peng, 02 \\
\hline Hua, Wenshen, 03 & SU, YU, OL \\
\hline Huang, Jie, OA & Sui, Xin, OC \\
\hline Huang, Zhulong, $O Q$ & Sun, Hongwei, 06, 07, OB \\
\hline Jia, Qingsong, 04, 07, 08, OB & Tan, Zhongqi, oX \\
\hline Jiang, Huilin, 06, 07, 08, OB, OR & Tang, Xiaojun, 00 \\
\hline Jie, Liang, OK & Wang, Chao, 00 \\
\hline Jin, Guangyong, $\mathrm{OQ}$ & Wang, Chao, OS \\
\hline Jin, Liang, 05 & Wang, Diankai, OA \\
\hline Kan, Zhi-jun, OU & Wang, Gang, 00 \\
\hline Kang, Hongxiang, OK & Wang, Jia-zan, OU \\
\hline Kong, Lingjiang, 09 & Wang, Jing, 02 \\
\hline Li, Dechun, OM & Wang, Lei, $O Q$ \\
\hline Li, Guiqiu, OM & Wang, Pei, OL \\
\hline $\mathrm{Li}$, Jing, OA & Wang, Shuang, Ol \\
\hline Li, Jing, OV & Wang, Tianshu, 04, 06, 07, 08, OB \\
\hline Li, Pingxue, OD & Wang, Wentao, 00 \\
\hline Li, Qiushi, OC, OT & Wang, Xiao-lin, OE \\
\hline Li, Xin, 02 & Wang, Xiaoman, OR \\
\hline Li, Yingchao, OS & Wang, Zhiyong, OV \\
\hline Lian, Fu-qiang, ou & Wei, Zhipeng, OW \\
\hline Lin, Yixiang, OJ & Wen, Guan-yu, Ol \\
\hline Liv, Gang, 00 & Wu, Dengsheng, ON \\
\hline Liu, Guojun, OW & Xiao, Feng, 09 \\
\hline
\end{tabular}


Xiong, Sheng-jun, OP

$\mathrm{XU}, \mathrm{BO}, \mathrm{OG}$

$\mathrm{XU}, \mathrm{Li}, 05$

Yang, Chun, OD

Yang, Kejian, $\mathrm{OM}$

Yang, Zhenming, 09

Yao, Yifei, OD

Yi, Bokai, OF

Yin, Xianyin, OG

Yu, Kai, $O Q$

Yu, Miao, $O Q$

Zhai, Ruizhi, $0 Q$

Zhai, Xuhua, OC

Zhang, Guangju, OD

Zhang, Hai-kun, 02

Zhang, He, 05

Zhang, Hongtao, OC

Zhang, Jing, OU

Zhang, Jun, ON

Zhang, Ke, OL

Zhang, Lizhong, 06, OS

Zhang, Peng, 04, 06, 07, 08, OB

Zhang, Xiongjun, ON

Zhao, Guomin, OF

Zhao, Shengzhi, OM

Zhao, Ziqiang, OD

Zheng, Jiangang, ON

Zheng, Kuixing, ON

Zhi, Dong, OE

Zhou, Cheng, 02

Zhou, Pu, OE

Zhou, Xuanfeng, OF

Zhou, Yanmin, OT

Zhou, Yijun, $\mathrm{OH}$

Zhou, Zhengren, 0J

Zhu, Baojing, $0 \mathrm{G}$

Zhu, Qihua, ON

Zou, Yonggang, 05

Zu, Chengkui, OG 


\title{
Symposium Committees
}

\author{
Symposium Chairs
}

Guofan Jin, Tsinghua University (China)

Songlin Zhuang, University of Shanghai for Science and Technology (China)

Conference Committee

Bingheng Lu, Xi'an Jiaotong University (China)

Byoungho Lee, Seoul National University (Republic of Korea)

Daren Lv, Institute of Atmospheric Physics (China)

David Webb, Aston University (United Kingdom)

Dianyuan Fan, Shanghai Institute of Optics and Fine Mechanics

(China)

Feng Zhang, Academy of Chinese Aerospace Science and Industry Feihang Technology (China)

Gaurav Sharma, University of Rochester (United States)

Guangjun Zhang, Beihang University (China)

Huitao Fan, Luoyang Optoelectro Technology Development Center (China)

Huixing Gong, Shanghai Institute of Technical Physics (China)

Jannick Rolland, University of Rochester (United States)

Jianquan Yao, Tianjin University (China)

Jiaqi Wang, Changchun Institute of Optics, Fine Mechanics and Physics (China)

Jingshan Jiang, Center for Space Science and Applied Research (China)

Junhao Chu, Shanghai Institute of Technical Physics (China)

Lijun Wang, Changchun Institute of Optics, Fine Mechanics and Physics (China)

Lin Li, Laser Processing Research Centre, The University of Manchester (United Kingdom)

Liwei Zhou, Beijing Institute of Technology (China)

Ming C. Leu, Missouri University of Science and Technology

(United States) 
Norbert Kaiser, Fraunhofer Institute for Applied Optics and Precision

Engineering (Germany)

Qifeng Yu, National University of Defense Technology (China)

Qingxi Tong, The Institute of Remote Sensing and Digital Earth (China)

Shouhuan Zhou, North China Research Institute of Electro-optics

(China)

Tianchu Li, National Institute of Metrology (China)

Ting-Chung Poon, Virginia Polytechnic Institute and State University (United States)

Wei Wang, Beijing Institute of Aerospace Control Devices (China)

Zuyan Xu, The Technical Institute of Physics and Chemistry (China)

Program Committee

Songlin Zhuang, Chair, University of Shanghai for Science and Technology (China)

Huaming Wang, Co-chair, Beihang University (China)

Huikai Xie, Co-chair, University of Florida (United States)

Jannick Rolland, Co-chair, University of Rochester (United States)

Jürgen Czarske, Co-chair, Dresden University of Technology

(Germany)

Yongtian Wang, Co-chair, Beijing Institute of Technology (China)

Anatoli G. Borovoi, V.E. Zuev Institute of Atmospheric Optics

(Russian Federation)

Bincheng Li, Institute of Optics and Electronics (China)

Binghen Lu, Xi'an JiaoTong University (China)

Byoungho Lee, Seoul National University (Republic of Korea)

Changxiang Yan, Changchun Institute of Optics, Fine Mechanics and

Physics (China)

Dae Wook Kim, The University of Arizona (United States)

David Webb, Aston University (United Kingdom)

Dawei Zhang, University of Shanghai for Science and Technology

(China)

Dong Liu, Anhui Institute of Optics and Fine Mechanics (China)

Fugen Zhou, Beijing University of Aeronautics and Astronautics (China)

Gaurav Sharma, University of Rochester (United States)

Geert Verhaeghe, Faurecia Autositze GmbH (Germany)

Guangya Zhou, National University of Singapore (Singapore)

Haimei Gong, Shanghai Institute of Technical Physics (China)

Jin Lu, Tianjin Jinhang Institute of Technical Physics (China)

Jun Zhou, Shanghai Institute of Optics and Fine Mechanics (China) 
Kai Cheng, Brunel University (United Kingdom)

Ligong Zheng, Changchun Institute of Optics Fine Mechanics and Physics (China)

Lijun Wang, Changchun Institute of Optics, Fine Mechanics and Physics, (China)

Lin Li, Laser Processing Research Centre, The University of Manchester (United Kingdom)

Ming C. Leu, Missouri University of Science and Technology (United States)

Minlin Zhong, Tsinghua University (China)

Mircea Guina, Tampere University of Technology (Finland)

Norbert Kaiser, Fraunhofer Institute for Applied Optics and Precision Engineering (Germany)

Pu Wang, Beijing University of Technology (China)

Roland Winston, University of California (United States)

Rongbing W.B. Lee, The Hong Kong Polytechnic University (Hong Kong, China)

Shulian Zhang, Tsinghua University (China)

Ting-Chung Poon, Virginia Polytechnic Institute and State University (United States)

Wei Wang, Beijing Institute of Aerospace Control Devices (China)

Wenli Ma, The Institute of Optics and Electronics (China)

Yi Luo, Tsinghua University (China)

Yiqin Ji, Tianjin Jinhang Institute of Technical Physics (China)

Yong Bi, Academy of Opto-electronics (China)

Yong Cheng, Wuhan Ordnance Non-Commissioned Officers Academy (China)

Yongnian Yan, Jiangsu YONGNIAN Laser Forming Technology Co., Ltd. (China)

Zhichuan Niu, Institute of Semiconductors (China) 
Proc. of SPIE Vol. $9294929401-10$

Downloaded From: https://www.spiedigitallibrary.org/conference-proceedings-of-spie on 25 Apr 2023 Terms of Use: https://www.spiedigitallibrary.org/terms-of-use 


\title{
Conference Committee
}

\author{
Conference Chairs
}

Lin Li, Laser Processing Research Centre, The University of Manchester (United Kingdom)

Pu Wang, Beijing University of Technology (China)

Jun Zhou, Shanghai Institute of Optics and Fine Mechanics (China)

Lijun Wang, Changchun Institute of Optics, Fine Mechanics and Physics (China)

Yong Cheng, Wuhan Ordnance Noncommissioned Officers School (China) 
Proc. of SPIE Vol. $9294929401-12$

Downloaded From: https://www.spiedigitallibrary.org/conference-proceedings-of-spie on 25 Apr 2023 Terms of Use: https://www.spiedigitallibrary.org/terms-of-use 


\section{Introduction}

We had the great honor of organizing the International Symposium on Optoelectronic Technology and Application 2014 (IPTA 2014) in Beijing. It was truly a great pleasure for us to greet nearly 1,000 participants from many different countries attending IPTA 2014! We firmly believe that the symposium will become an important international event in the field of photoelectronic technology.

IPTA 2014 was sponsored by Chinese Society of Astronautics (CSA) and China Hightech Industrialization Association, technically co-sponsored by SPIE, and organized by Photoelectronic Technology Committee, Chinese Society of Astronautics. 27 cooperating organizations supported the conference. There were nearly 600 papers accepted for presentation at IPTA 2014, contributed by over 1078 authors from more than 10 countries, including United States, United Kingdom, Germany, France, Norway, Australia, Canada, Japan, Korea, Russia, and China. We had six plenary speeches and 228 well-known scientists and experts, from both home and abroad to give invited talks at different sessions.

The purpose of IPTA 2014 was to provide a forum for the participants to report and review innovative ideas, with up-to-date progress and developments, and discuss the novel approaches to application in the field of photoelectronic technology. We sincerely hope that the research and development in the optical and photoelectronic fields will be promoted, and international cooperation sharing the common interest will be enhanced.

On behalf the Organization Committee of IPTA 2014, we would like to heartily thank our sponsors and cooperating organizations for all they have done for the conference. We would also like to thank the authors for their contribution to the proceedings; the participants and friends of IPTA 2014, for their interest and efforts in helping us to make the symposium possible; and the Program Committee for their effective work and valuable advice, especially the IPTA 2014 Secretariat and the SPIE staff, for their tireless efforts and outstanding services in preparing the conference and publishing the Proceedings.

\section{Guofan Jin \\ Songlin Zhuang \\ IPTA 2014 Symposium Committee Chairs}


Proc. of SPIE Vol. $9294929401-14$

Downloaded From: https://www.spiedigitallibrary.org/conference-proceedings-of-spie on 25 Apr 2023 Terms of Use: https://www.spiedigitallibrary.org/terms-of-use 